\title{
FUERO ANTIGUO DE LA MERINDAD DE DURANGO
}

\author{
Adrián Celaya Ibarra
}

Con un brevísimo comentario y con la denominación de Fuero antiguo se inserta el texto del Fuero de Durango en el tomo II de la Historia de Bizkaia de Labayru. Dada la autoridad de nuestro primer historiador, nadie ha puesto en duda su autenticidad, aunque este sorprendente documento plantea algunas incógnitas. ${ }^{1}$

Podemos preguntarnos por su fecha, que no se aclara en el propio texto, pues Labayru lo toma de un traslado hecho en 1746 en Avellaneda, del archivo de las Encartaciones de Bizkaia. No soy historiador por lo que he de apoyarme en opiniones ajenas; y me agrada recordar la de D. Andrés Mañaricua a quien oí decir que, a su juicio, el texto podía ser del siglo XIV y quizá remontarse al XIII.

A juzgar por su contenido y muy especialmente por su lenguaje, debe ser muy anterior al Fuero de Bizkaia de 1452, y probablemente a los Cuadernos de Hermandad de 1342 o al penal de 1395. Las instituciones se exponen de forma distinta y más imperfecta que en las leyes que he citado y, a mi juicio, en forma más embrionaria, $\mathrm{y}$, sin duda, esto denota más antigüedad.

Se ha afirmado que el presunto Fuero es una recopilación privada, y sin prejuzgar nada, considero esta opinión muy probable, por varias razones: No contiene ningún preámbulo que nos dé fe de su elaboración, a diferencia de todos los textos forales que conocemos en Bizkaia; es algo desordenado y mezcla, sin separación, normas civiles, pe-

1 No debe confundirse este Fuero con el concedido en 1150 por Sancho IV de Navarra a los labradores censuarios de la merindad de Durango. Aunque Iturriza y otros escritores lo denominan Fuero, es algo muy limitado, se refiere únicamente a los labradores censuarios y sus disposiciones tratan exclusivamente de los tributos que dichos labradores deben dar al Señor. 
nales y políticas. Es lo más probable que una mano anónima se detuviera a escribir las viejas costumbres, para valerse de ellas en la práctica, sin detenerse en criticarlas o modificarlas. Este hecho quizá conceda mayor valor a la recopilación para el conocimiento del Derecho más antiguo, pues garantiza la vigencia de las costumbres duranguesas desde épocas anteriores. La mano anónima que redactó este texto dejó acreditado que Durango tenía usos y costumbres del mayor interés y que, sin duda, se estaban aplicando desde hacía tiempo. Son costumbres que guardan un gran paralelismo con el Fuero de Vizcaya de 1452, pero que evidentemente están en una fase más primitiva de su formación, por lo que podemos suponer que el llamado Fuero de la Merindad rigió en Durango en fechas remotas. Mi falta de preparación histórica me impide profundizar en esta cuestión, por lo que me limitaré a analizar el texto desde un punto de vista exclusivamente jurídico, atendiendo básicamente a su contenido $\mathrm{y}$, en algún caso, comparándolo con otras normas vizcaínas.

Desde este punto de vista, me parecen muy acertadas las palabras de Díez Unzueta cuando afirma que el Fuero de la Merindad de Durango «tiene un contenido amplio, rico y variado, compuesto de materias civiles y penales, lo que permite hablar de una verdadera ordenación $\mathrm{u}$ ordenamiento jurídico, de un auténtico bloque normativo» ${ }^{2}$.

Hay que añadir que este Fuero tiene un evidente parentesco con los Fueros de Bizkaia y de las Encartaciones, cuyo texto y formación son más conocidos. En los Fueros de la merindad de Durango aparecen ya, en embrión, las más importantes instituciones del Derecho vizcaíno, y ello se manifiesta en la casi totalidad de sus normas. Al leerlas, se tiene la impresión de que iguales, o muy similares, debieron ser las más antiguas costumbres del Señorío. Y aunque es cierto que la merindad de Durango no formó parte de la más primitiva Vizcaya, cuyo núcleo es Guernica, también puede sostenerse que el Duranguesado no fue a remolque de las instituciones de Bizkaia, sino que participó en su elaboración en la misma medida que dicho núcleo central.

Quizá por haber escapado a la atención de los juristas vascos, que ni siquiera lo utilizaron en las fechas inmediatas a su inclusión en la hermosa obra de Labayru, los comentarios sobre el Derecho de Bizkaia no citan hasta tiempos muy recientes el texto de este Fuero, cuando buscan antecedentes a sus instituciones. Hoy podemos acariciar este Cuaderno de costumbres, difundido en varias ediciones, como si se

2 Ignacio Díez Unzueta, «Comentario jurídico al Fuero antiguo de la merindad de Durango», en Cuadernos de Historia Duranguesa, pág 41. Esta publicación incluía el texto íntegro del Fuero de la Merindad de Durango. 
acabara de descubrir, con el asombro y el agrado de ver ante nosotros un especial precedente del Derecho vizcaíno histórico, cuyos primeros pasos descubrimos en el Duranguesado, y, al menos en el orden civil, con formulaciones más modernas, aún permanece vigente. No hay ningún antecedente más antiguo de las leyes de Bizkaia.

En este breve estudio, no puedo tener la pretensión de agotar el contenido de tan interesante texto jurídico, ni siquiera de acertar en este breve análisis, pues voy a ocuparme tan sólo de algunas cuestiones concretas que considero más trascendentales. Lo hago con un respeto emotivo hacia el texto que descubrió Labayru y desdeñando el temor de equivocarme, como casi siempre ocurre en las primeras exploraciones. Es preferible concederle un recuerdo cariñoso aunque sea erróneo, que relegarlo al olvido.

Expondré especialmente, porque ésta es la materia que mejor conozco, lo que el Fuero de Durango supone en relación con el Derecho Privado.

\section{A. Paralelismo con el Fuero de Bizkaia en materia civil}

Aunque existan opiniones diversas sobre el origen del Derecho civil vasco, y en especial el vizcaíno, estimo indiscutible que su formación se debe a influencias diversas, pero básicamente nace en el tronco común pirenaico o vascón, lo que le relaciona con el Derecho aragonés, el navarro o el vigente en los territorios del Norte del Pirineo, singularmente los territorios vascos de Iparralde. En el aspecto político, este Derecho mantiene una organización básicamente democrática ${ }^{3}$, cuyo órgano legislativo y de gobierno se plasma en Asambleas territoriales como las Juntas Generales de Bizkaia, Guipúzcoa y Alava, el Biltzar de Ustaritz, el Silviet de Soule, las Juntas de Sarobe en Ayala o, las Juntas de otros territorios que se adhirieron a Bizkaia como las de Avellaneda en las Encartaciones o las de Astola y Guerediaga en el Duranguesado.

En el campo del Derecho Civil son características del sistema la unidad familiar y la troncalidad que se manifiestan en Bizkaia en tres

3 Cuando hablo de una organización democrática no me estoy refiriendo a la democracia en el sentido moderno, que nace de la Revolución iniciada en el siglo XVIII en Francia y los Estados Unidos. La palabra democracia, y esencialmente también su significado, fue inventada por los griegos, y se suele atribuir a algunas formas políticas pasadas, como los pequeños cantones suizos o la Carta Magna inglesa. De hecho, nunca se ha conocido una situación perfectamente democrática, y el mundo actual camina hacia ella, aunque esté lejos de haberla alcanzado. 
instituciones presentes también en el Fuero del Duranguesado: a) La transmisión íntegra del caserío a un solo heredero, no impuesta por la ley sino regulada como una facultad del propietario: b) Un régimen de comunidad de bienes en el matrimonio, con una fuerte posición del viudo ante los herederos; c) La troncalidad, fuertemente acentuada en las ventas y enajenación de bienes patrimoniales.

En el Cuaderno de Durango que aquí examino aparecen de forma notable estas notas distintivas, que preludian lo que más tarde sería el Fuero de Bizkaia, que con respecto a las normas civiles vigentes en Durango no parece que innovara casi nada importante.

\section{Libre designación de heredero}

Como ocurre en Navarra o en el valle de Ayala, el Fuero de Bizkaya concede al testador la facultad de elegir libremente su heredero, pero con la notable diferencia de que únicamente lo puede elegir entre los hijos o sucesores, nunca entre extraños. La misma libertad de testar se recoge en el Fuero de Durango, cuya primera ley ${ }^{4}$ dispone que los hijos hereden por partes iguales cuando no hay testamento; pero «si fuere la voluntad del testador, que pueda mejorar a qualquier de los hijos de quanto por bien tobier é que los otros hermanos non le puedan poner demanda».

Esta norma es muy similar a la del Fuero de Bizkaia (capítulo CXII) pero hay una diferencia, pues éste distingue entre los bienes muebles y los inmuebles o raíces, y permite disponer libremente de los primeros (capítulo CXI del Fuero de 1452), reservando los inmuebles o raíces para los herederos. Una distinción, probablemente de origen germánico, para la que la costumbre de Durango no puede servir de precedente. El Fuero de Durango no hacía esta distinción pues la primera ley se aplica a «todos los otros bienes que fueren así muebles como raíces».

En cambio, hay una vieja costumbre vizcaína que el Fuero de Durango regula de forma mucho más clara y terminante que las primeras leyes de la Bizkaia nuclear. Todos los comentaristas reconocen que el uso habitual en los caseríos consiste en transmitir la hacienda a uno de los hijos reservándose los padres donantes el usufructo o el derecho de alimentos, lo que de acuerdo a la moderna técnica constituye un pacto sucesorio. El Cuaderno de Durango recoge esta costumbre como habitual y obligatoria, aunque no se haya pactado, pues se entiende, según

${ }^{4}$ La edición de Labayru, y la copia que utilizó, no numera las leyes; tomo la numeración de la edición de la Diputación Bizkaiko Foru Legeria, Bilbao 1991, que reprodujo el texto de Labayru, numerando las leyes para facilitar su cita. 
la ley 2 y las que siguen, que si los padres donan el caserío, al hijo designado sucesor, éste debe «le dar su mantenimiento en toda su vida e de le facer sus enterrorios y cumplimientos según Fuero de Durango» y en caso de querella de los padres ordena que se fije la cuantía de los alimentos «por dos homes buenos hijosdalgo y un home bueno que sea labrador é que si fuere lugar labradoriego que sean los dos homes buenos labradores y el uno fijodalgo». La ley 3 ordena que del mismo modo se le dé al donante «su vestir».

Además, en las leyes 4 y 5 se reconoce al cónyuge superviviente un verdadero derecho de viudedad, un derecho que trabajosamente se ha ido regulando en las leyes vizcaínas hasta la vigente ley de 1992. Dice la ley 4 que «si morier el marido o la muger que el que fincare vivo que haya poder de tener en su poder la mitad de todos los bienes así muebles como raíces», "para facer de ello lo que haya menester empero que non haya poder de enajenar la raíz».

Y la ley 5 defiende al viudo frente a los posibles abusos de los hijos para que «le non puedan toller la su mitad en toda la su vida» y para que pueda «estar en la dicha casería sobre los dichos bienes que hubieren marido y muger de consuno y cuando morier que le entierren é hagan sus enterrorios y cumplimiento sobre lo que dicho es».

\section{E1 régimen de bienes en el matrimonio}

En los regímenes forales vascos, como en Aragón y a diferencia de Cataluña, una vez contraído matrimonio se establece un sistema de comunidad de bienes entre los cónyuges, que generalmente, como ocurre en Aragón o Navarra, se limita a los bienes ganados o conquistados. Sin embargo, en Bizkaia, la comunidad se extiende a todos los bienes, tanto los ganados como los heredados o adquiridos por cualquier otro título, lo que conocemos como comunidad universal.

La comunidad de bienes, que en Bizkaia se conoce como comunicación foral, puede producir un conflicto con la troncalidad, según la cual los bienes procedentes de la familia han de transmitirse a los hijos o herederos y no al cónyuge, y éste ha sido uno de los problemas más complicados que planteaba la interpretación y aplicación del Fuero. El Fuero de las Encartaciones de 1503 resolvía la cuestión ordenando que todos los bienes se comuniquen con excepción de los bienes raíces, respecto de los cuales mandaba que los cónyuges «se aprovechen de ello comunmente pero que despues de la vida de cualquier dellos que el que fincare vivo que se vaya con su tronco enteramente», salvo que se hayan hecho «ameateros» por carta. La excepción la constituye el llamado Fuero de vecino, vigente en los territorios de Somorrostro, Galda- 
mes, Sopuerta, Carranza y Trucíos, donde aunque el marido y la mujer no se hayan hecho ameateros «que el que vivo queda goza por su vida el usufructo é despues de sus días vuelve la tal raíz al tronco». En este supuesto, aplicable a una amplia zona encartada, su costumbre se aproxima a la del Fuero de Durango.

Es bastante evidente que el sistema de comunidad universal rige también en el Duranguesado, pues claramente se ordena (ley 4) que a la muerte del marido o de la mujer «el que fincare vivo haya la mitad en su poder». Se exceptúan los bienes raíces (que son los que hoy llamamos troncales, porque en los Fueros anteriores al de 1526 no se usa la palabra troncalidad) Dice esta ley que, pese a que el viudo toma la mitad de los bienes «que non haya poder de enagenar la raíz», lo que supone que tiene los bienes raíces en una especie de usufructo que se extingue por la muerte para transmitirlos a los herederos tronqueros. Algo muy similar a lo que ocurre en el Fuero de vecino de las Encartaciones.

El Fuero Viejo de Bizkaia (1452) establecía la comunicación de bienes en todo caso, haya o no hijos del matrimonio, y aunque no aparezca tan claro se puede llegar a la misma conclusión en el Fuero del Duranguesado. La ley 5 se refiere en primer lugar al caso de que haya hijos y ordena que éstos no puedan «toller» los bienes del viudo en toda su vida «si quier vivir y estar en la dicha casería con los dichos bienes»; pero, a continuación permite que el viudo pueda abandonar el caserío y poner en tal lugar casero «si no hubiere hijos, y si hubiere fijos que non pueda poner ninguno en renta ni en otra manera que sea». Es decir, que hay comunicación, haya o no hijos, aunque siempre con la reserva de que los bienes raíces han de reservarse al tronco, lo que es un claro indicio de la vigencia de la troncalidad, pese a que esta materia no se desarrolle más extensamente.

\section{La troncalidad}

De las dos leyes citadas se desprende que, de forma más o menos intuitiva, la troncalidad está presente en el Fuero del Duranguesado, y en algún otro texto aparece con más claridad.

Es de destacar especialmente el paralelismo entre la regulación de la venta de bienes raíces en el Fuero de Durango y en el Fuero Viejo de Bizkaia, en el que los llamamientos forales y la saca foral son uno de sus rasgos más distintivos.

La necesidad de los llamamientos forales en las ventas, la tasación por hombres buenos, y el pago del precio a plazos están contenidos en la ley 34 del Fuero de Durango que dice así: 
«34. Otrosí cualquier fijodalgo o labrador que hobier de vender tierra ó heredad que sea tenido de llamar en la Anteiglesia que se hubier de facer la tal venta que el vendedor lo faga saber al que tobiere lugar ó mayor grado é que le diga si quiere comprar la tal heredad é si quiere comprar el que mayor grado tobier que le pague el precio de contia á vista de tres homes buenos é que los dichos homes buenos que manden que el dicho precio por ellos apreciado y declarado que el comprador le dé al vendedor dentro del año en tres tercios é otro ninguno que sea de fuera parte que no lo pueda comprar é si lo comprare la tal venta non vala.»

El Fuero Viejo de Bizkaia regula los llamamientos y ventas con mucho más detenimiento en sus capítulos LXXIX a XCV, pero su doctrina es casi idéntica a la que resumidamente se encuentra en las costumbres de Durango. Puedo apreciar las siguientes similitudes:

a) La venta o enajenación de bienes raíces exige previamente los llamamientos forales en la Anteiglesia. La ley 34 se refiere únicamente a las ventas, pero la ley 36 deja bien claro que la misma norma se aplica a otras enajenaciones: «que ninguno non pueda vender, nin endonar nin trocar ninguna casería ni terreno nin heredad queriendolo tanto por tanto el propincuo... pagando por ello el precio ó el trueque el tal propincuo a precio de hombres buenos». No indica el cuaderno de Durango la forma en que se publicarán los llamamientos y ni siquiera si han de repetirse en varios domingos, como exige el Fuero Viejo de Bizkaia, y se limita a decir que ha de llamarse en la Anteiglesia, lo que entiendo que significa la iglesia parroquial.

b) La tasación se ha de hacer por tres hombres buenos, como en el Fuero Viejo. El Fuero Nuevo (ley 1 del título XVI) especifica que cada parte nombrará un hombre bueno y un tercero lo dará el juez (el alcalde de fuero, según el Fuero Viejo). No se hacen estas concreciones en el sintético Fuero de Durango, y ni siquiera se habla de la intervención del juez.

c) Tanto la ley 34 como la 36 afirman que los únicos que pueden acudir a los llamamientos son los propincuos «é otro ninguno que sea de fuera parte que non lo pueda comprar». Estos propincuos son los que hoy llamamos tronqueros, y el Fuero Viejo trataba de definirlos en su capítulo LXXXV diciendo que "por propincuos hayan el pariente mas cercano que viene de la línea de donde procede la tal heredad é non otro ninguno».

d) El precio fijado, según la ley 34 se ha de pagar dentro del año en tres tercios, lo que supone un aplazamiento que el Fuero Viejo recogía en los propios términos, «faga la paga en tres tercios del año». 
En definitiva, parece claro, por el testimonio de este «fuero antiguo» como le llamó Labayru, que los principios básicos del derecho de saca regían en el Duranguesado bastante antes de la aprobación del Fuero de 1452, que muy bien pudo afirmar que sus leyes eran cosa «que habían de Fuero, uso y costumbre».

\section{B. El Derecho penal en el Fuero de Durango}

Para juzgar de las penas en el Derecho antiguo o medieval hay que tener en cuenta las circunstancias y las costumbres, así como la fiereza de ciertas ideas dominantes hasta la aparición de la nueva ciencia penal en el siglo XVIII. Nos impresiona su terrible crueldad, pero hay que considerar las dificultades que aquella sociedad tenía para luchar contra el delito, cuando no existía policía alguna e incluso eran desconocidas las penas de prisión, salvo con carácter preventivo, como ocurre con la «cadena» que citan nuestros fueros.

Aquellas penas durísimas hieren nuestra sensibilidad, y no tiene hoy interés detenerse a analizarlas. La durísima crítica de Beccaria y la de su anotador Voltaire ${ }^{5}$ removieron la conciencia de Europa, reivindicaron el principio de legalidad, humanizaron las penas y las hicieron proporcionales a la gravedad de los delitos.

No tiene sentido hacer la dura crítica de aquellas leyes que surgen en un contexto tan diferente del actual. Haré simplemente un comentario sobre la similitud existente entre los distintos textos forales y el de Durango, haciendo observar que éste es bastante anterior.

La defensa de la propiedad rural es en Bizkaia una seria preocupación de las leyes forales. Se defienden los cultivos y arbolados, y entre ellos especialmente los manzanos por el gran aprecio no sólo de su fruto sino de la sidra. El Fuero de Durango dice en su ley 29 que «si algun home cortare en heredad agena pies de manzano de tres en arriba que muera por ello»; en la misma línea el Fuero de las Encartaciones (ley 8 del Título II) disponía que «aquel cualquier que entornare é vertiera la sidra agena que otro obiere encerrada y lo faciera a sabiendas cortando ó foradando la cuba en tal manera que la sidra de la cuba sea vertida toda é la mayor parte de ella que lo maten por ello».

5 El italiano CESARE DE BeCCARIA publicó su libro Dei delitti e delle pene en 1765 haciendo una crítica profunda del sistema penal y penitenciario del antiguo régimen, que ha sido probablemente el origen del moderno Derecho Penal. El libro, difundido pronto entre los intelectuales franceses fue comentado por Voltaire en 1769 y se difundió por toda Europa. 
Este rigor se suaviza cuando se trata de otra clase de árboles. Así, la ley 27 condena a quien corta sauces, al pago de doce maravedís, y la ley 28 eleva la pena cuando se trata de roble, acebo o fresno, a cuarenta y ocho maravedís, pero la reduce a doce maravedís cuando se corta níspero, higuera o cerezo u otros semejantes. Observamos que en el Fuero Viejo de Bizkaia, el capítulo XLV es más riguroso, pues la pena de muerte se impone al «que cortare o arrancare de cinco manzanos arriba, ó de cinco nogales arriba que llevan fruto, o de cinco viñas arriba, a sabiendas»; además impone en todo caso la pena de cuarenta y ocho maravedís, incluso tratándose de «cerezos é guindales, nisperos y robles, é fresnos, é sales». Es difícil creer que los redactores de este Fuero no tuvieran presentes los precedentes del Duranguesado.

El robo se castiga durísimamente. El Fuero del Duranguesado ordena que al ladrón «le corten las orejas é si fuere hallado otra vez en este caso que lo maten por ello» (ley 64). Un rigor similar al que emplea el Cuaderno penal de $1342^{6}$ cuando dispone que «el robador ó ladrón que fuere tomado en cuerpo y carne, que lo maten por ello», con lo que sin duda se refiere al ladrón cogido «in fraganti», pero más adelante, sin exigir el requisito de flagrancia, añade que «si alguno quebrantare casa o la foradare que le maten por ello» ${ }^{7}$.

En esta línea se pronuncia también el Cuaderno de Hermandad de 1395, aunque supone un avance. Lo que parece una disposición inhumana de este Cuaderno es en realidad una suavización de la pena, pues en su capítulo $6^{8}$ ordena que qualquier que a otro robare en el camino de cinco florines arriba que muera por ello y en el capítulo séptimo añade que el hurto fuera del camino sea castigado también con la muerte cuando sea de diez florines arriba. Es curioso que al fijar esta cifra se recurre a una moneda que no pertenece al común sistema castellano de doblas, dineros o maravedís, sino al florín, que era una moneda de

6 Tomo esta cita del texto del Capitulado de 1342 otorgado en Junta presidida por D. Juan Núñez de Lara, según el texto que publicó LABAYRU, en su Historia General de Bizkaia, tomo II, págs. 403 a 408 y que, según dice en el encabezamiento, se recoge del escrito solicitado por los hombres de Albia o república de Abando en 1366. El texto no aparece dividido en capítulos o leyes, aunque en algunos lugares se introduce la palabra «título» pero no existe numeración alguna, lo que dificulta la cita.

7 Normas igualmente severas aparecen en el Fuero de Ayala. La ley XVIII dice que «qualquiera que quebrantare camino o robase, pague seiscientos maravedís, é al dueño el doble, e si fuere tomado en el día, que lo maten por ello». Y la ley XX que «qualquier hombre hidalgo que fuese tomado con cuero é carne, e con fecho de hurto o de robo muera por ello».

8 Cito el «Cuaderno de Hermandad» de 1495 por Labayru, Historia General de Bizkaya, Tomo II, págs. 497 a 509, donde el articulado está dividido en párrafos numerados, que en el encabezamiento se denominan capítulos y en el texto títulos. 
oro, introducida en España por catalanes, navarros y aragoneses y, sin duda, valiosa. La suma de diez florines debía ser una cantidad respetable en aquel tiempo ${ }^{9}$ y probablemente nadie la llevaría por un camino sin escolta o protección ${ }^{10}$.

El Fuero Viejo en su capítulo LI reconoce que la pena de muerte por un hurto de diez florines arriba está establecida en «el cuaderno de Vizcaya» (se refiere al de 1395) pero añade que esto solamente ocurre si «el querelloso» sigue la vía penal, pues si elige la vía civil, el acusado deberá pagar doblada la cantidad hurtada. De esta manera la aplicación de la pena de muerte queda a la decisión del ofendido.

¿Hasta qué punto tuvieron vigencia estas leyes? Es muy significativo a este respecto el acuerdo tomado en las Juntas Generales de Bizkaia el 11 de febrero de 1506 (en el acta que se denominó «reformación del Fuero») en cuyo punto $8 .^{\circ}$ se dice que «hay otra ley de la Hermandad que dispone que cualquiera que hurtare o robare de diez florines arriba muera por ello». Y a esta disposición le hace tres objeciones: a) que es muy rigurosa; b) que es contra la disposición del derecho así común como del reino; y c) que «nunca ha sido usada nin guardada, mas antes por el contrario uso está abrogada é derogada, según la información que sobre ello se ha habido é recibido de letrados, é de otras personas espertas é esperimentadas». Por ende «ordenaron que por el primer hurto si non fuere enorme é grande en calidad el tal ladrón é malhechor non pudiera nin pueda ser condenado a pena de muerte».

A los historiadores toca aclarar si es cierto que esas penas tan duras no se usaron, si se usaron solamente contra el enemigo personal, o si la suavización de las costumbres en el final de las guerras de bandos, for-

9 Téngase en cuenta que la competencia en materia civil de los alcaldes de Fuero no alcanzaba sino al límite de cuarenta y ocho maravedís, cantidad notoriamente inferior, aunque calculada en moneda castellana.

10 Es algo intrigante el hecho de que se haya fijado en florines la suma que determina la gravedad de un robo. Seguramente Vizcaya se movía entre el sistema monetario castellano y el aragonés o navarro pues no tuvo nunca acuñación propia. El florín de oro creado en Florencia en 1252 tuvo durante años una gran difusión en toda Europa pues su peso se mantenía constante. Posteriormente otros países lo acuñaron, como Francia en tiempos de Felipe IV (1285 - 1314), Aragón en tiempos de Pedro IV (1355 - 1387) y en cantidades muy pequeñas en Navarra lo acuñó Carlos II (1285 - 1314). Sería de gran interés poder determinar la clase de florines a la que se refieren las leyes forales, si eran los italianos, los franceses, los aragoneses o los navarros; pero no es posible evitar la confusión que produce la utilización del florín frente al sistema castellano de doblas, reales, dineros o maravedís, que está más presente en el Fuero. (Estos datos me han sido facilitados por la Dra. D. ${ }^{a}$ María Angeles Larrea). 
zaba a los reunidos en la Junta de 1506 a hacer una declaración más generosa. Lo que resulta evidente es que el Texto conocido como Fuero de Durango se mueve en el contexto vivo de las diversas legislaciones que fueron produciéndose en Vizcaya y que finalmente se fundieron en el Fuero de 1526.

\section{Las clases sociales en el Fuero de Durango}

No es fácil de creer que la distinción entre señores y siervos no se diera en otros tiempos en el País Vasco, y que todos los vascos disfrutaran de una nobleza originaria surgida desde el paraíso terrenal; pero lo cierto es que, especialmente en el siglo XVI, los escritores vizcaínos, con una clara intención reivindicativa, porque concedía a todos los vascos algunos derechos que en otros territorios se negaban a una parte de la población, mantuvieron la tesis de la nobleza universal a la que buscaron orígenes muy antiguos, incluso emparentándola con los godos o llevando nuestra genealogía hasta Noé. Fue éste un valiente y patriótico trabajo de los hombres de aquella época, que con su labor no solamente constataban la existencia en nuestro País de una mayor igualdad, y un mayor aprecio de los trabajos que en otros lugares llamaban serviles, sino que pretendían que, tras la incorporación a Castilla, mantuvieran los vizcaínos los derechos que la ley castellana solamente reconocía a los hidalgos.

Probablemente por razones interesadas, y por los servicios que los vizcaínos les prestaron, la reclamación de hidalguía encontró la mejor acogida en los reyes de la casa de Austria, y especialmente de Felipe II. La hidalguía supuso no solamente la prohibición de la tortura y una serie de privilegios procesales, como la necesidad de un mandato judicial para ordenar la prisión o la prohibición de que los ejecutores entraran en la casa del vizcaíno, etc., sino también la posibilidad de ocupar cargos y oficios en la Corte o en el ejército y la armada de Castilla.

Pero los vascos no somos un fenómeno extraño en el teatro de la Historia. Nacimos y vivimos con las dificultades y problemas de todos los demás pueblos, y no se puede suponer que en la antigüedad existiera entre nosotros una igualdad civil esencial que en ninguna parte del mundo existió, aunque a partir de la Edad Media haya testimonios de una profunda aspiración popular hacia la generalización de los derechos básicos.

Planteada así la cuestión es interesante investigar el camino que llevó a nuestros antepasados a proclamar abiertamente el dogma de la universal hidalguía, la idea tan difundida de que todos los vascos so- 
mos hidalgos o nobles. Todo induce a creer que el Pueblo Vasco llegó a esa conclusión, no sin trabajo, y en diversas etapas históricas ${ }^{11}$.

Nuestra historia escrita es tan reciente que no es fácil encontrar en ella signos de la esclavitud romana o la condición de siervos que existió en la Edad Media europea. Sin embargo, una situación similar a la que en Castilla u otros reinos tenían ciertas personas que, sin ser siervos sino colonos, quedaban adscritas al cultivo de una tierra, de la que no podían desligarse, es lo más probable que se diera también en Vizcaya, de forma parecida a otros territorios españoles. Y quizá partiendo de una situación en la que los hombres libres conviven con otros que no lo son o no plenamente, se inicia una evolución hacia el reconocimiento de la dignidad humana, en el que el Fuero del Duranguesado puede arrojar bastante luz.

En el Fuero de Ayala de 1373 está claramente establecida la distinción entre hidalgos y labradores o peones. Los peones no pueden «levantar casa» (ley XXX) y si la levantan puede el Señor o cualquier hidalgo ocuparla y tenerla como suya; se ponen dificultades al matrimonio entre peones e hidalgos, pues la mujer que casa con un peón pierde la hidalguía (ley XLIII), es más grave la pena por herir al hidalgo que al labrador (ley LXVIII y LXIX) y lo mismo ocurre en otros delitos. Se había avanzado muy poco hacia la libertad.

En el Fuero de Durango se mantiene también la distinción de hidalgos y labradores, aunque mi impresión es que la separación no debió ser tan tajante como en el Fuero de Ayala. Lo que el Fuero durangués distingue claramente es que hay tierras labradoriegas y tierras de hidalgos o infanzonas, pero, aunque no se equiparan ambas clases, los labradores poseen derechos y deberes muy similares a los de los hidalgos ${ }^{12}$.

11 Los escritores vascos desde el siglo XVI, con el deseo de justificar la nobleza universal de los vizcaínos declaraban a los vascos como los primeros pobladores de España, venidos con Túbal, nieto de Noé y aseguraban, que la lengua vasca fue hablada en el Paraíso terrenal (por ejemplo, el licenciado Poza).

12 El Fuero del Duranguesado alude también a los «ruanos», los de la calle, habitantes de la villa, de quienes no se ocupa ninguno de los Fueros de Vizcaya. Se puede afirmar que el Fuero de la merindad de Durango es en este punto más realista, y no olvida a los hombres de vida urbana, que entonces no pasaría de ser rústicamente urbana, pero en tiempos posteriores se desarrolló tanto el urbanismo que puede decirse que sus diferencias con la zona rural son determinantes en la historia de Vizcaya. Por supuesto que, las declaraciones de hidalguía, que se hacen en 1526 con gran generalidad, les alcanzan también, aunque no les citen expresamente.

No veo fácil descifrar la ley 55 del Fuero, aunque es un reconocimiento de que existe un Fuero distinto en la villa. La ley 60 se refiere a fijosdalgo, labradores y ruanos indistintamente para prohibirles querellarse ante el alcalde de Durango, y aquí ya asoma el posible conflicto entre los dos Fueros. Esto se aprecia también en las referencias a la Junta de Guerediaga, a las que no se convoca a los ruanos. 
La posición de los labradores parece más libre que en otros lugares. Por ejemplo, los labradores acuden a las Juntas de Guerediaga igual que los hidalgos, lo que constituye un derecho político incompatible con la calidad servil. Así lo dispone la ley 71, que curiosamente desde el día de San Juan a la Virgen de Setiembre hace obligatoria la asistencia a la Junta, como ejercicio de un deber ciudadano. La diferencia de clase se muestra únicamente en que el hidalgo que no acude incurre en una multa de veinticuatro dineros, y, en cambio la multa para el labrador es de dieciséis.

Otra curiosa diferencia entre las dos clases sociales aparece en las leyes 44 y 45 del cuaderno de Durango. Ambas prohíben, tanto al hidalgo como al labrador que «trayan más de una yegua domada», por lo que en principio hay igualdad, pero el hidalgo «puede traer con esta yegua dos fijos»; y si el tercero «le naciera que lo venda y saque de la casa donde nació». En cambio, el labrador puede tener la yegua con su hijo «é despues que otro fijo le nacier que lo venda y heche el primero fijo é si trae mas yeguas de lo que dicho es que lo tome el Señor é las haya por suyas». Da la impresión de que la yegua hace el papel del caballo en Castilla, cuyo uso se niega a los plebeyos porque el caballo distingue al hidalgo, pero, como se ve, no ocurre esto en Durango, sino que simplemente se limita su posesión.

Pero el punto más revelador de la situación del labrador se encuentra en la ley 15 en la que se hace una separación entre los lugares labradoriegos e infanzonados. La ley es muy oscura, pero creo encontrar claras las siguientes conclusiones: a) Que un hidalgo puede heredar de sus padres en los lugares labradoriegos; b) que, en cambio, no puede heredar de hermanos que quedan en el lugar labradoriego, y que sobre dichos bienes sucede el hermano que queda en dicho lugar (me queda la duda de si el hidalgo instalado en tierra labradoriega pierde la hidalguía); c) que los labradores pueden suceder también en lugares infanzonados con las mismas limitaciones. A lo que parece las tierras de infanzonado son para los hidalgos y las labradoriegas para los labradores.

Lo que era esencial en los labradores medievales es su obligación de permanecer en la tierra labradoriega y no poder abandonarla, una obligación de la que fue poco a poco liberándose en Castilla a través de disposiciones de los reyes en las que generalmente se pone un precio a esta libertad. No encuentro una disposición que en el Duranguesado obligue al labrador a permanecer en su tierra, aunque acaso existiera en otro tiempo. Puede inclinarnos a opinión contraria la extensión que el Fuero da al derecho de sucesión en favor indistintamente de hidalgos o labradores (ley 2) y el derecho de saca foral que también se reconoce a todos, con la única diferencia (ley 36) de que si el lugar fuere de infanzonado, los hombres buenos sean dos hidalgos y un labrador, y si fuera 
labradoriego, dos labradores y un hidalgo. Ante los derechos de propiedad, las dos clases sociales se encuentran en condiciones similares. Si el labrador puede heredar, aunque sea tierra labradoriega o ejercitar el derecho de saca, ello significa no solamente que puede tener bienes suficientes para la adquisición sino también que puede dejar su tierra para acudir a la que adquiere. En definitiva, me parece lo más probable que estos labradores, como los que contempla la escritura duranguesa de 1050, también llamada Fuero, son labradores censuarios, que están obligados a pagar al Señor una renta, pero que pueden abandonar el solar, salvo que el titular del censo sea el Señor, como se descubre en las leyes posteriores dictadas en Vizcaya para someter esas casas a Fuero aunque se hallen en las villas, impidiendo que puedan ser divididas con el riesgo de que se abandonen y no se pague el censo al Señor.

Hay también diferencias en cuanto a la composición y multas en algunos delitos, pero quizá la más importante, porque es una característica propia del derecho de hidalguía está en la ley 42, que prohíbe al prestamero, merino o sayón acercarse a más de cuatro brazas de la casa del hidalgo para «prendar» (entiendo que es para practicar un embargo) y si lo hace permite que el hidalgo le exija las veinte vacas por la injuria. Pero lo desconcertante de esta ley es que, a renglón seguido afirma que el sayón que demande las prendas fuera de las cuatro brazas «si más adelante entrare» que lo mate el hijodalgo sin pena; y si «al fijodalgo o labrador le prendare por cualquier cosa fuera de los pedidos del Señor y le alcanzare yendo con las prendas» ... «y si en defendimiento de ellas acaeciere que fiera al sayón que non haya pena por ello». Es el primer texto vizcaíno en que aparece esta notable disposición de respeto a la propia morada, que luego se repite en los Fueros y que permite afirmar, como en Inglaterra, que la casa de un hombre es su castillo.

También existen algunas diferencias entre hidalgos y labradores en la cuantía de las multas y composición de los delitos.

En los años posteriores Vizcaya entera, y no solamente el Duranguesado, camina hacia el reconocimiento de la hidalguía para todos, que termina con esta distinción medieval.

En los Cuadernos de Hermandad de 1395 no aparece ninguna diferencia entre hidalgos y labradores, ni se establecen penas o composiciones distintas para unos $\mathrm{u}$ otros. Ciertamente estos Cuadernos tienen un carácter preferentemente penal, pero pueden ser un signo de que se avanza hacia un mayor sentido de la dignidad general de toda persona. Un paso mucho más importante lo supone el Fuero Viejo de 1452, en el que todos los privilegios y derechos propios de los hidalgos se establecen, sin distinción, en favor de todos los vizcaínos, y si alguna vez se 
habla de hidalgos y labradores es para equipararlos, como ocurre en el capítulo XVI a propósito de la libertad de comprar y vender.

La diferencia importante entre hidalgos y labradores, la encuentro en el capítulo CCVIII que se ocupa de los labradores que cultivan tierras que deben pagar un censo al Señor, un censo que se fija en una cantidad global que se reparte entre todos los censatarios y la falta de pago de unos repercute sobre los demás. Es en este caso cuando se ordena algo que tiene todavía un fuerte resabio medieval, y que marca aún la diferencia de clases. Los tales labradores deben continuar cultivando las tierras labradoriegas y pueden ser requeridos para ello por el prestamero o merino.

Pocos años después, da la impresión de que el labrador no tiene ninguna obligación de permanecer en la finca que cultiva, y que la abandona cuando quiere, incluso si se trata de un censuario que depende del señor de Vizcaya. En 17 de marzo de 1487 los Reyes Católicos en una Pragmática se percatan de que los labradores censuarios abandonan las casas, por lo que no cobran sus rentas, pero ni siquiera piensan en forzarles a habitarlas, sino que atribuyen los casos de abandono al hecho de estar situadas las fincas censuarias en las villas, sujetas al Fuero Real de Castilla, y a que la aplicación de las leyes castellanas fomenta la división de los caseríos, que por sucesivas divisiones pueden hacerse poco rentables. En consecuencia, autorizaron a estos labradores para que, aun siendo vecinos de villa puedan mandar y dejar sus casas y caserías a cualesquier de sus hijos e hijas que quisieren según y como lo hacen los otros labradores de la Tierra Llana. En definitiva admiten que se aplique el Fuero de Bizkaia aunque estos caseríos estén situados en una villa. Con esta medida esperan conseguir «que los dichos nuestros solares labradoriegos en todo tiempo estén enteros y fogueras vivas y no se despueblen ni yermen». Esta disposición fue recogida en el Fuero Nuevo, ley 2 del título XXXVI, y curiosamente no se toma ninguna medida sobre las casas censuarias situadas fuera de las villas, ya que, al parecer, la aplicación del Fuero era para los Señores suficiente garantía.

La proclamación solemne de la hidalguía con carácter universal se hace finalmente de forma clara y terminante en diversos lugares del Fuero de 1526. Cito por su contundencia la ley XVI del título I en la que se dice «Que todos los naturales, vecinos y moradores de este dicho Señorío de Vizcaya, Tierra Llana, Encartaciones é Durangueses, eran notorios hijosdalgo é gozaban de todos los privilegios de homes fijosdalgo...» ${ }^{13}$.

13 Entre el Fuero de 1452 y el de 1526 ocurren acontecimientos importantes. Bizkaia tuvo una impecable relación con los Reyes Católicos y con los primeros reyes de la casa de 
Con esta declaración del Fuero, la hidalguía universal parecía conquistada, pero aún hubo de sufrir otras pruebas, y la más conocida se produjo cuando el fiscal Juan García en su libro De hispanorum nobilitate... afirmó que los vizcaínos podrán ser honrados, pero no hidalgos, porque para ser hidalgos «es necesaria en la misma provincia la distinción de pecheros, lo que no hay en Vizcaya». Contra este libro se alzaron las Juntas de Guernica en 24 de julio de 1588 y Felipe II atendiendo a su demanda ordenó en una cédula dictada en 30 de enero de 1590 que se recogieran todos los ejemplares y se enmendaran tachando los párrafos que ponían en entredicho la hidalguía vizcaína.

La hidalguía declarada para Vizcaya parecía a extenderse a todos los conocidos entonces como vizcaínos, tanto los guipuzcoanos como los alaveses ${ }^{14}$; pero la hidalguía de los guipuzcoanos fue declarada por Felipe III en cédula real de 6 de junio de 1610; y más tarde se declaró que «son iguales en su esencia los fueros de Alava y los de Vizcaya y Guipuzcoa, por eso gozan las tres hermanas de las mismas libertades y franquezas, aunque literalmente no consten en el fuero de alguna de ellas» (Real decreto de 2 de febrero de 1644).

La hidalguía no solamente eximía a los vizcaínos del pago de tributos no acordados en las Juntas, prohibía aplicarles la tortura, o hacerlos presos sin mandato judicial, y les daba otras libertades establecidas en los Fueros, sino que además les permitió participar, en igualdad con los hidalgos castellanos, en las empresas que emprendía el rey de Castilla, en América, o en Europa, y ocupar puestos en los despachos reales. Eran un buen número los que fueron secretarios del rey, y sobre ello ironizaban Quevedo y Cervantes. Cuando Sancho Panza busca un secretario, Cervantes hace decir a uno de los presentes: «-Yo señor, que sé leer y escribir y soy vizcaíno.» Y Sancho añade: «—Con esa añadidura bien puedes ser secretario del mismo emperador.»

La lucha por la hidalguía, de la que el Fuero del Duranguesado es uno de los primeros escalones, es también la lucha por la dignidad hu-

\footnotetext{
Austria y quizá fue esta la razón de que sus Fueros no solamente se respetaran sino que se reafirmaran en la redacción de 1526 y especialmente en la definición de la hidalguía universal; pero también tuvieron los vizcaínos que hacer concesiones, pues la reina exigía que se permitiera que el obispo entrara en Vizcaya, lo que prohibía el Fuero de 1452; y, por otra parte, la expulsión de los judíos obligó a los vizcaínos a aceptar una provisión real de 8 de setiembre de 1511 que prohibía a judíos y moros avecindarse en Vizcaya. Esta provisión fue incluida en la ley 13 del título I del Fuero, porque la admisión de judíos y moros resultaba incompatible con el mantenimiento de la limpieza de sangre que la hidalguía exigía.

14 A todos se les conocía impropiamente como vizcaínos; el vizcaíno que luchó con don Quijote era de Azcoitia.
} 
mana, por la libertad y los demás valores que el mundo actual alaba tanto, y que no hubieran sido concebibles si no se hubieran ganado paso a paso. Y hoy es preciso seguir avanzando por la misma senda.

Resulta bastante evidente el papel que el documento que Labayru publicó como Fuero antiguo de la merindad de Durango, representa en el estudio de nuestras antiguas leyes. Aporta elementos valiosísimos para el estudio de la evolución de las costumbres de Vizcaya en todos los campos, e incluso en éste de la nobleza universal. Simplemente me interesa hacerlo notar para que personas más competentes nos lleven a un mayor esclarecimiento de un pasado que aún pone su huella en la disposición adicional 1. ${ }^{\mathrm{a}}$ de la Constitución española. 